\title{
IRON HOMEOSTASIS REGULATING FACTORS IN HEPATITIS C
}

\author{
Atef Amer $^{1}$; Yousri Aboelmagd ${ }^{2}$ and Mohamed Elshahat ${ }^{3 *}$ \\ ${ }^{1}$ professor of organic chemistry, depatment of chemistry, faculty of science, zagazig \\ university. \\ 2 professor of biochemistry,department of biochemistry , faculty of medicine, zagazig \\ university . \\ 3 master student, depatment of chemistry, faculty of science, zagazig university. \\ *Corresponding author : Elshahat304@gmail.com
}

Key words :Hepcidin,HCV,Iron,liver,fibrosis,cirrhosis .

\begin{abstract}
:
Hepcidin is the central regulator of systemic iron homeostasis. Dysregulation of hepcidin production results in a variety of iron disorders. Hepcidin deficiency is the cause of iron overload in hereditary hemochromatosis, iron-loading anemias, and hepatitis C. Hepcidin excess is associated with anemia of inflammation, chronic kidney disease and ironrefractory iron deficiency anemia. The main objective of this study is to elucidate the correlation between Hepcidin and Iron as adiagnostic biomarkers in Hcv infected patients . infection with hepatitis c virus is amajor cause of choronic liver disease , many experimental and clinical studies suggest that excessive iron in $\mathrm{CHC}$ is a cofactor promoting the progression of liver damage and increasing the risk for fibrosis. This study contain two groups; Group I (healthy subjects): This group included fifteen healthy persons with ages ranged (33-63) years, they had no history of liver disease which may interfere with the studied parameters, This group represents $30 \%$. Group II : This group included thirty five patients infected with hepatitis $\mathrm{C}$ virus, their ages range from 41 to 76 years, This group represents $70 \%$.All clinical individuals in this study were collected from Outpatient Clinics of Zagazig University Hospitals. The following parameters ; Complete blood pictures, Liver functions tests, Kidney functions tests, Hepcidin levels and Iron levels were performed for all groups. The obtained result revealed asignificant decrease of hepcidin in $\mathrm{HCV}$ infected patients compared to the control group Also, asignificant increase in Iron level in infected patients compared to control group .
\end{abstract}

\section{INTRODUCTION:}

Hepatitis $\mathrm{C}$ virus (HCV) belongs to genus Hepacivirus, family Flaviridae, and it is a small positive strand RNA, enveloped virus. HCV is one of the main etiological agents of progressive liver diseases resulting in liver cirrhosis and hepatocellular carcinoma. Infection by HCV is the main cause of chronic liver diseases, mainly fibrosis, cirrhosis and liver failure as well as hepatocellular carcinoma that affect about 170 million people all 
over the world (Flamm et al., 2003). In Egypt, the prevalence of HCV is the highest worldwide (Frank et al., 2000) with an estimated prevalence of $14.7 \%$ among the general population during 2008 (El-Zanaty and Way, 2009).

Accumulation of iron in liver is common in HCV infection results in liver fibrosis and increased risk of hepatocellular carcinoma (Lambrecht et al., 2011). HCV Patients have a relative low hepcidin level compared to uninfected peoples (Fujita et al., 2007) resulting in unrestricted duodenal iron absorption and iron release from macrophages through the iron transporter ferroportin (Nemeth and Ganz, 2009).

The human hepcidin gene (HAMP) encodes a precursor of hepcidin - preprohepcidin that is 84 amino acid proteins. Preprohepcidin is cleaved to give 60 aa prohepcidin that gives rise to hepcidin. Hepcidin: 25 aa, 22 aa and 20 aa peptide are the three forms of hepcidin. These three forms can be detected in urine, but hepcidin- 25 and hepcidin- 20 only present in human serum (Rossi, 2005). The major form of hepcidin is hepcidin- 25, which contains 8 cysteine residues conjugated by disulfide bonds (Krause et al., 2000).

So, hepcidin is considered as the master regulator of iron homeostasis. Generally, it decreases the level of iron in serum. This mechanism depends mainly on the interactions between hepcidin and ferroportin. Ferroportin, the only known mammalian cellular iron exporter, is expressed on the surface of hepatocytes, reticulo- endothelial macrophages.

\section{EXPERIMENTAL:}

All clinical individuals in this study were collected from Outpatient Clinics of Zagazig University Hospitals.

\section{Subjects:}

Fifty individuals were included in this study. Group I (healthy control), This group included fifty healthy persons with ages ranged (33-63) years, they had no history of liver disease, malignant tumors or any other diseases which may interfere with the studied parameters, This group represents $30 \%$ and the second group, included thirty five patients infected with hepatitis $\mathrm{C}$ virus, their ages range from 41 to 76 years, This group represents $70 \%$.

\section{Methods:}

All groups were subjected to Complete blood pictures ( $\mathrm{CBC}$ ),Liver functions tests ( L.F.T), Kidney functions tests (L.F.T), Hepcidin and Iron levels.Complete blood count (CBC)Was done on automated cell counter, [ XS 500i (Sysmex, Japan) ] , Liver and kidney functions were done by using biomed reagents, hepcidin was determined using Human Hepc25(Hepcidin 25) ELISA Kit supplied by Elabscience Biotechnology Inc and The quantitative determination of Iron by means of particle- 
enhanced turbidimetric immunoassay using Spectrum Kit supplied by Egyptian Company for Biotechnology (S.A.E).

\section{RESULTS AND DISCUSSION:}

Hepatitis $\mathrm{C}$ virus (HCV) is considered as a major health problem worldwide because HCV patients are at risk of progressive liver disease that favors the generation of long term complications such as cirrhosis, end stage liver disease and hepatocellular carcinoma (Spengler and Nattermann, 2007). Egypt has one of the highest prevalence of hepatitis $C$ in the world. $\mathrm{HCV}$ genotype 4 is the most common strain in Egypt followed by HCV genotype 1 (90\% and 10\% respectively) (Bazeed et al., 2016)

The liver is the main iron storage organ and it plays a fundamental role in iron metabolism. The iron transport protein, transferrin, and the major iron storage protein, ferritin, are both synthesized in the liver. Iron homeostasis is critical for human because iron is an essential element necessary for many basic biological processes; however, excess iron may also be highly cytotoxic. Elevated serum levels of iron represent early markers for the severity of liver disease.

Hepcidin is synthesized in the liver and it is thought to be a key regulator for iron homeostasis. It is induced mainly by infection and inflammation. Hepcidin expression levels in chronic liver diseases were strongly correlated with either the serum ferritin concentration or degree of iron deposits in the liver (Farid et al., 2012).

The aim of the present study is evaluation of hepcidin level and its relation with iron state in HCV infected patients. Serum samples were collected from control (non HCV) individuals and diseases (HCV infected patients) for determination of liver function test (Total bilirubin, Albumin, ALT and AST), kidney function test (Blood urea and creatinine), CBC (Platelets, WBCs, RBCs and $\mathrm{Hb}$ ), iron and iron binding capacity as well as determination of hepcidin level and its relations with the previous parameters in Table 1 and Fig 1.

Table (1): Statistical analysis of complete blood count $(\mathrm{CBC})$ in control and diseased samples.

\begin{tabular}{|l|c|c|}
\hline CBC & Control $(n=15)$ & Diseased $(n=35)$ \\
\hline Platelets $\left(\times 10^{6} / \mathrm{L}\right)$ & $362.47 \pm 11.57$ & $301.69^{* * *} \pm 11.84$ \\
\hline WBCs $\left(\times 10^{9} / \mathrm{L}\right)$ & $5.37 \pm 1.05$ & $6.03 \pm 1.05$ \\
\hline RBCs $\left(\times 10^{12} / \mathrm{L}\right)$ & $4.67 \pm 1.01$ & $4.15^{* * *} \pm 1.02$ \\
\hline Hemoglobin $(\mathrm{g} / \mathrm{dL})$ & $13.08 \pm 0.21$ & $11.98^{* *} \pm 0.16$ \\
\hline
\end{tabular}

n: Number of examined samples.

Means with ** lables means that HCV group having are highly significant different than control means $(P<0.01)$

** Highly significant 
Bilirubin is a yellowish substance resulted from the breakdown of hemoglobin, which is the major component of RBCs. Chemical analysis of liver function tests revealed that total bilirubin level in control samples was $0.76 \pm 0.04 \mathrm{mg} / \mathrm{dL}$, while in HCV patients; it was $0.79 \pm 0.04 \mathrm{mg}$ / dL (Table 2 and Fig. 2).

This result was in line with many authors; Wahib et al. (2006) who studied twenty HCV/PCR-RNA positive patients and found that total bilirubin increased in 7 patients (35\%) and Souza et al.,(2006) who reported that hyperbilirubinemia has been associated with $\mathrm{HCV}$

Albumin is produced only by the liver and it is the major protein, which circulates in the blood. It is important to maintain the oncotic pressure in the vascular system. Any decrease in the oncotic pressure as a result of low albumin, fluid leak from the interstitial spaces into the peritoneal cavity, causing ascites (Nagao and Sata, 2010). Albumin is also very important in the transportation of many molecules; such as free fatty acids, bilirubin, hormones and drugs.

As illustrated in Table 2 and Fig. 3, serum albumin was 3.8 in control samples, while it was 3.5 in $\mathrm{HCV}$ patients. HCV patients were highly significant different than control samples $(\mathrm{P}<0.01)$. This result was in accordance with Nagao and Sata (2010) who reported low albumin level $(<4.0 \mathrm{~g} / \mathrm{dL})$. A low serum albumin concentration is an indicator on poor liver function.

Data found in Table 2 and Fig. 4, showed that the level of aspartate aminotransferase (AST) was $27.67 \pm 1.33$ in control samples, while this level elevated in HCV patients $(36.66 \pm 1.95)$, therefore, HCV patients were highly significant different than control samples $(\mathrm{P}<0.01)$. This result agreed with Wahib et al., (2006) who reported that AST increased in $15 \%$ of HCV patients and Bazeed et al. (2016) who reported an extremely significant increased AST in HCV patients (42.7 U/L).

The level of alanine aminotransferase (ALT) was $23.44 \pm 3.55$ and $28.84 \pm 1.07$ in control and HCV patients, respectively (Table 2 and Fig. 6). This result was in line, who concluded that in HCV patients, alterations in the liver tissue is reflected by ALT elevation and mainly associated with periportal bridging/necrosis, viral load and duration of disease. Reported an elevation in ALT in HCV patients (56 U/L), as well as Bazeed et al. (2016) who reported an extremely significant increased ALT in HCV patients (50 U/L), who demonstrated that during recent HCV infection, higher ALT levels were detected.

This result could be attributed to when parenchymal liver cells are damaged, aminotransferases leak from the liver into the blood, resulting in elevated levels of these enzymes in the bloodstream. 
Table (2): Statistical analysis of liver function tests in control and diseased sampl

\begin{tabular}{|c|c|c|}
\hline Liver function tests & Control $(\mathbf{n}=15)$ & Diseased $(\mathbf{n}=35)$ \\
\hline BIL T (mg/dL) & $\mathbf{0 . 7 6} \pm \mathbf{0 . 0 4}$ & $\mathbf{0 . 7 9} \pm \mathbf{0 . 0 4}$ \\
\hline ALB (g/dL) & Median $=3.8$ & Median $=3.5^{* *}$ \\
IQR $=\mathbf{0 . 5 0}$ \\
\hline AST (U/L) & $27.67 \pm 1.33$ & $\mathbf{3 6 . 6 6} \pm 1.95$ \\
\hline ALT(U/L) & $23.44 \pm 3.55$ & $28.84 \pm 1.07$ \\
\hline
\end{tabular}

n: Number of examined samples.

Means with ** lables means that HCV group having are highly significant

different than control means $(P<0.01)$

** Highly significant

Results illustrated in Table 3 and Fig. 7, revealed that the level of blood urea was $26.33 \pm 1.45 \mathrm{mg} / \mathrm{dL}$ in control samples and this level decreased in HCV patients $(24.53 \pm 1.55 \mathrm{mg} / \mathrm{dL})$, while, creatinine level was $0.77 \pm 0.02$ and $0.83 \pm 0.01 \mathrm{mg} / \mathrm{dL}$ in control samples and $\mathrm{HCV}$ patients, respectively (Table 3 and Fig. 8).

Table (3): Statistical analysis of kidney function tests in control and diseased samples.

\begin{tabular}{|l|c|c|}
\hline kidney function tests & Control $(\mathrm{n}=15)$ & Diseased $(\mathrm{n}=35)$ \\
\hline Blood urea $(\mathrm{mg} / \mathrm{dL})$ & $\mathbf{2 6 . 3 3} \pm 1.45$ & $\mathbf{2 4 . 5 3 \pm 1 . 5 5}$ \\
\hline Creatinine $(\mathrm{mg} / \mathrm{dL})$ & $\mathbf{0 . 7 7} \pm \mathbf{0 . 0 2}$ & $\mathbf{0 . 8 3} \pm \mathbf{0 . 0 1}$ \\
\hline
\end{tabular}

n: Number of examined samples.

These findings were in line, who announced that HCV infection increases the rate of progression of CKD in patients with glomerulonephritis with an increase in serum creatinine $(1.3 \mathrm{mg} / \mathrm{dl})$.

Complete blood count (CBC) is one of the most commonly performed blood tests because it reveals the peripheral blood changes. It is routinely performed in health examinations, even in asymptomatic patients. The data present in Table 4 and Fig. 9, showed that platelets count was $362.47 \pm 11.57 \times 106 / \mathrm{L}$ in control samples, meanwhile this level decreased in HCV patients to be $301.69 \pm 11.84 \times 106 / \mathrm{L}$. The HCV patients were highly significant different than control samples $(\mathrm{P}<0.01)$.

This result was agreed with what had been reported, who illustrated that thrombocytopenia occurs in HCV infection and in liver cirrhosis. This result could be attributed to; HCV patients have low levels of serum thrombopoietin, which is mostly produced by the liver tissue before its release into the bloodstream and it is the main regulator of platelet production.

The WBCs count was $5.37 \pm 1.05 \times 109 / \mathrm{L}$ in control samples, while this count increased in HCV patients $(6.03 \pm 1.05 \times 109 / \mathrm{L})$ (Table 4 
and Fig. 10). This result agreed with, who reported that HCV infected group showed significantly higher WBC, lymphocyte, and monocyte counts compared with control group.

Hemoglobin level in control samples was $13.08 \pm 0.21 \mathrm{~g} / \mathrm{dL}$ but $\mathrm{HCV}$ patients had a lower level of $\mathrm{Hb}(11.98 \pm 0.16 \mathrm{~g} / \mathrm{dL})$ (Table 4 and Fig11\&12). A highly significant different was detected between HCV patients and control samples $(\mathrm{P}<0.01)$.

Table (4): Statistical analysis of iron and total iron binding capacity in control and diseased samples.

\begin{tabular}{|c|c|c|}
\hline tests & Control $(\mathrm{n}=15)$ & Diseased $(\mathrm{n}=35)$ \\
\hline Iron $(\mathrm{Ug} / \mathrm{dL})$ & $\mathbf{6 6 . 4 7} \pm \mathbf{2 . 1 3}$ & $\mathbf{1 1 9 . 4 3}^{* *} \pm 2.12$ \\
\hline TIBC (Ug/dL) & $\mathbf{3 7 9 . 7 8} \pm \mathbf{2 . 6 8}$ & $295.74^{* * *} \pm 1.47$ \\
\hline
\end{tabular}

n: Number of examined samples.

Means with ** lables means that HCV group having are highly significant

differentce than control means $(P<0.01)$

** Highly significant

This result agreed, who reported that HCV is associated with low levels of $\mathrm{Hb}$ compared with control group but disagreed, who reported that $\mathrm{HCV}$ infected group showed significantly higher Hb levels $(14.7 \pm 1.5 \mathrm{~g} / \mathrm{dl})$ compared with control group $(13.4 \pm 1.8 \mathrm{~g} / \mathrm{dl})$

The liver is the main iron storage organ because a third of the total iron of the body is deposited in hepatocytes, portal tracts, sinusoidal mesenchymal cells, and reticuloendothelial cells. Increased serum iron level and the decreased level of TIBC were correlated with progressive hepatic parenchymal disease.

Hepcidin hormone is mainly produced by the liver and released in circulation. When it reaches the circulation, it regulates the metabolism of iron by controlling iron transport to the duodenal enterocytes and iron export from the macrophages. So, it is the key regulator of iron metabolism and is a significant biomarker for systemic inflammatory states. Hepcidin acts by binding to iron carriers, causing internalization and lysosomal degradation (Nemeth, 2010) in Table 5.

Table (5): Statistical analysis of hepcidin level in control and diseased samples

\begin{tabular}{|c|c|c|}
\hline Test & Control $(\mathbf{n}=15)$ & Diseased $(\mathbf{n}=35)$ \\
\hline Hepcidin $(\mathbf{n g} / \mathbf{m L})$ & $\mathbf{8 1 . 4 9} \pm \mathbf{0 . 9 6}$ & $29.98^{* * *} \pm 1.03$ \\
\hline
\end{tabular}

n: Number of examined samples.

Means with ** lables means that HCV group having are highly significant differentce than control means $(P<0.01)$

** Highly significant

This result agreed with Fujita et al. (2007), Farid et al. (2012) who reported that hepcidin is significantly lower in HCV patient. 
The results found in Table 6 illustrated the correlation coefficient of relations between hepcidin and liver function test, kidney function test, $\mathrm{CBC}$, iron, total iron binding capacity and HCV. A highly significant correlation was detected between hepcidin and HCV, AST, platelets count, RBCs count, Hb, Iron and TIBC $(\mathrm{P}<0.05)$. These correlations were positive between hepcidin and platelets count, RBCs count, $\mathrm{Hb}$ and TIBC $(0.42,0.39,0.48$ and 0.94 , respectively), while negative correlations were detected between hepcidin and HCV, AST and iron ($0.65,-0.40$ and -0.87). Meanwhile, non-significant correlations were detected between hepcidin and BIL T, ALB, ALT, blood urea, creatinine and WBCs.

Table (6): Correlation coefficient of relations between hepcidin and liver function test, kidney function test, $\mathrm{CBC}$, iron, total iron binding capacity and HCV.

\begin{tabular}{|c|c|c|}
\hline & \multicolumn{2}{|c|}{ Hepcidin } \\
\cline { 2 - 3 } & r & P-value \\
\hline Age & -0.05 & $\mathbf{0 . 7 9 6}^{\text {NS }}$ \\
\hline BIL T & -0.09 & $\mathbf{0 . 5 9 0}^{\text {NS }}$ \\
\hline ALB & -0.07 & $\mathbf{0 . 6 5 6}^{\text {NS }}$ \\
\hline AST & -0.40 & $\mathbf{0 . 0 0 5}^{* *}$ \\
\hline ALT & -0.24 & $\mathbf{0 . 0 9 4}^{\text {NS }}$ \\
\hline B.Urea & 0.17 & $\mathbf{0 . 2 4 1}^{\text {NS }}$ \\
\hline CRET & -0.11 & $\mathbf{0 . 4 5 9}^{\text {NS }}$ \\
\hline PLT & 0.42 & $\mathbf{0 . 0 0 2}^{* *}$ \\
\hline WBCs & -0.26 & $\mathbf{0 . 0 7 3}^{\text {NS }}$ \\
\hline RBCs & 0.39 & $\mathbf{0 . 0 0 5}^{* *}$ \\
\hline HB & 0.48 & $\mathbf{0 . 0 0 0}^{* *}$ \\
\hline Iron & -0.87 & $\mathbf{0 . 0 0 0}^{* *}$ \\
\hline TIBC & 0.94 & $\mathbf{0 . 0 0 0}^{* *}$ \\
\hline HCV RNA by & -0.65 & $\mathbf{0 . 0 0 0}^{* *}$ \\
\hline PCR & &
\end{tabular}

r: correlation coefficient

0 to 0.2 weak relationship

0.3 to 0.6 moderate relationship

0.7 to1 strong relationship

** Highly significant, NS non-significant

These results agreed, but disagreed with Farid et al. (2012) who observed inverse correlations. These variations could be attributed to the differences in disease 


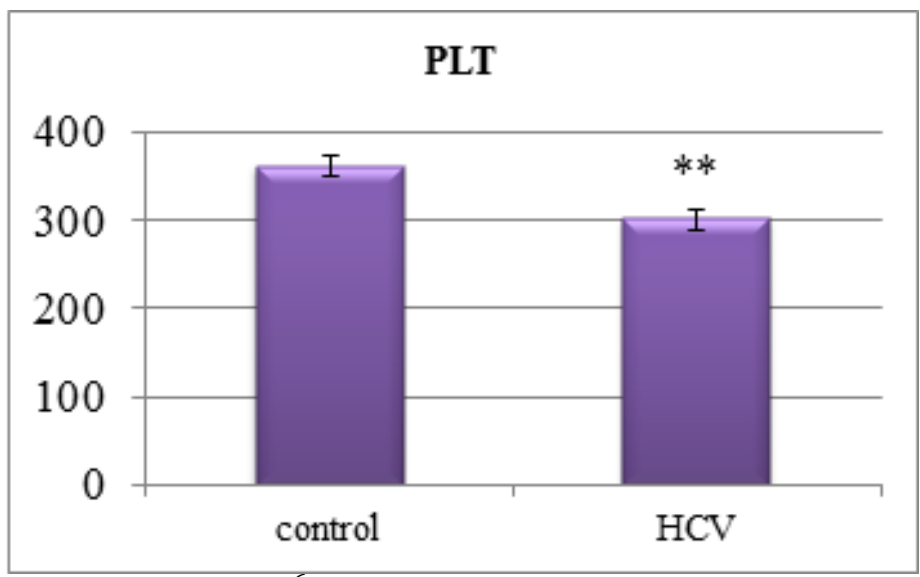

Fig. (1): Platelets $\left(\times 10^{6} / \mathrm{L}\right)$ count in control and diseased samples.

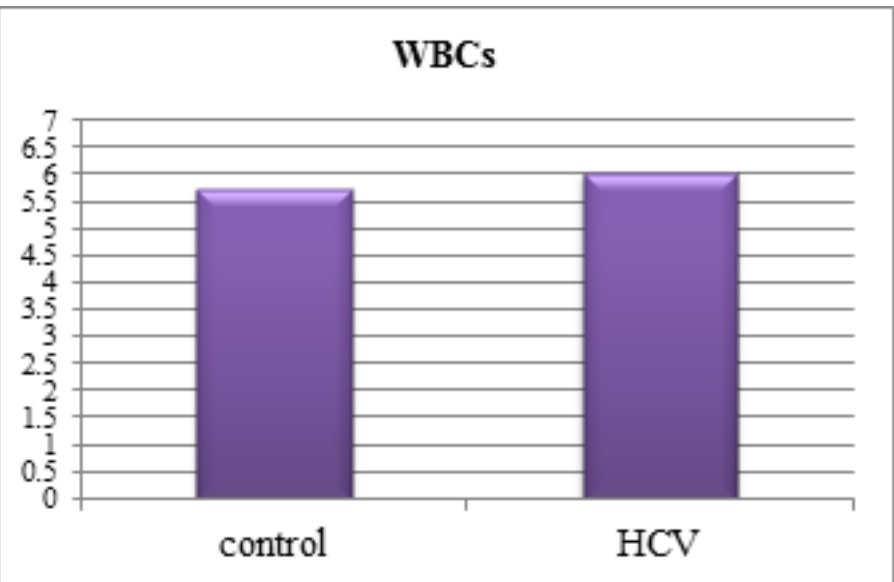

Fig. (2): WBCs count $\left(\times 10^{9} / \mathrm{L}\right)$ in control and diseased samples.

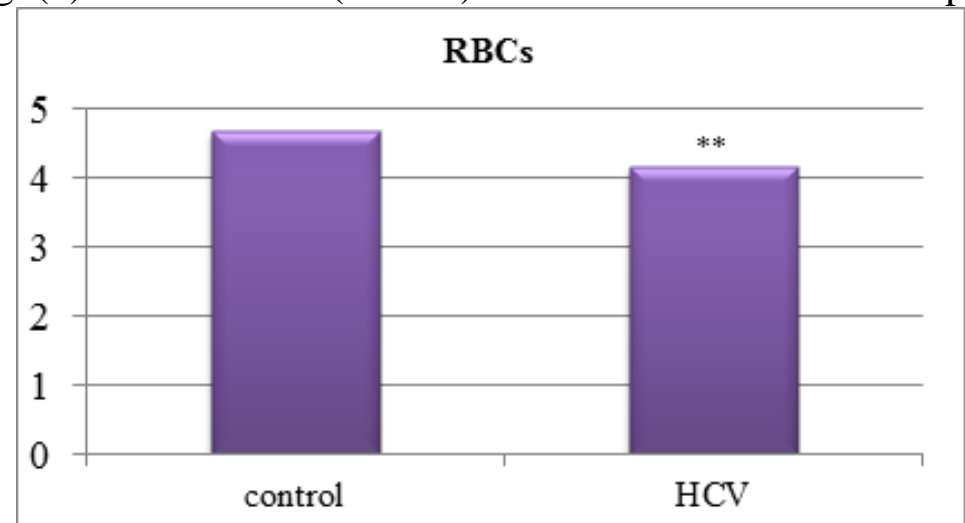

Fig. (3): RBCS count $\left(\times 10^{12} / \mathrm{L}\right)$ in control and diseased samples. 


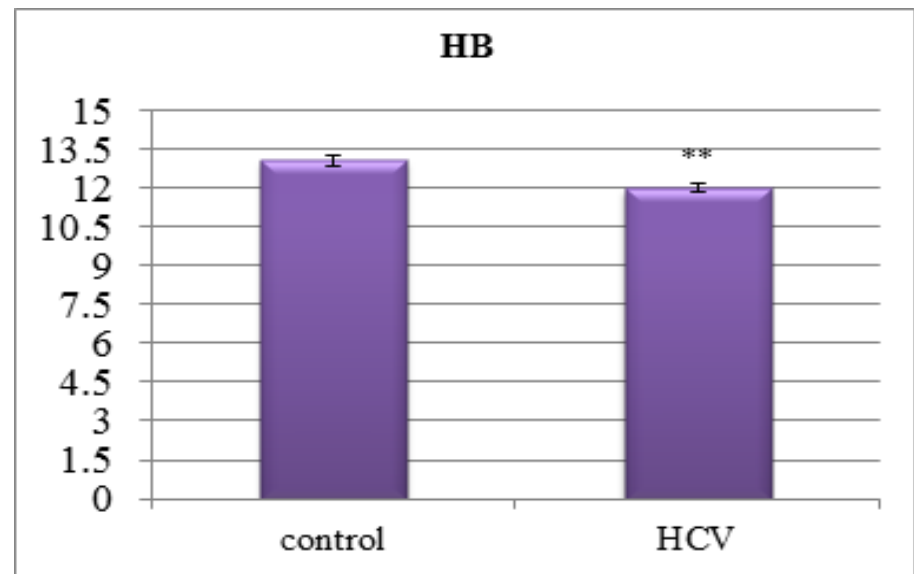

Fig. (4): Hemoglobin (g/dL)in control and diseased samples.

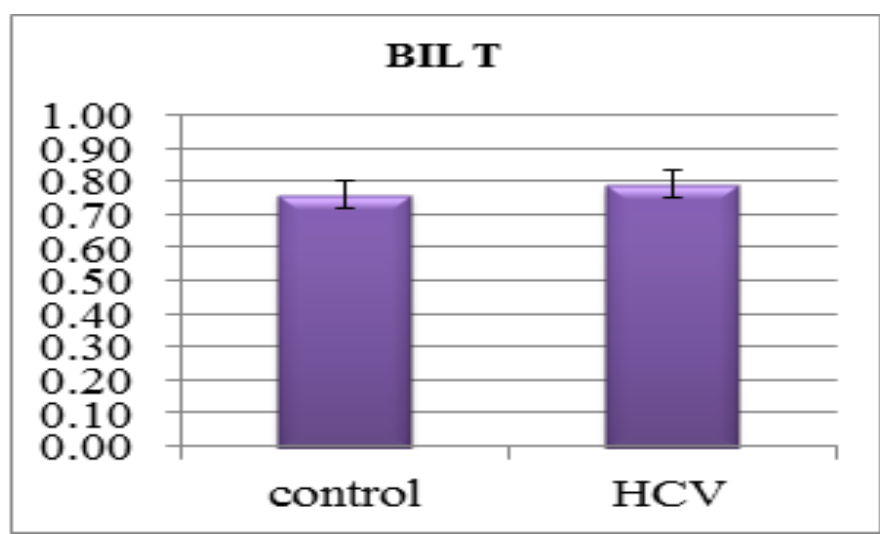

Fig. (5): Total bilirubin (BIL T)

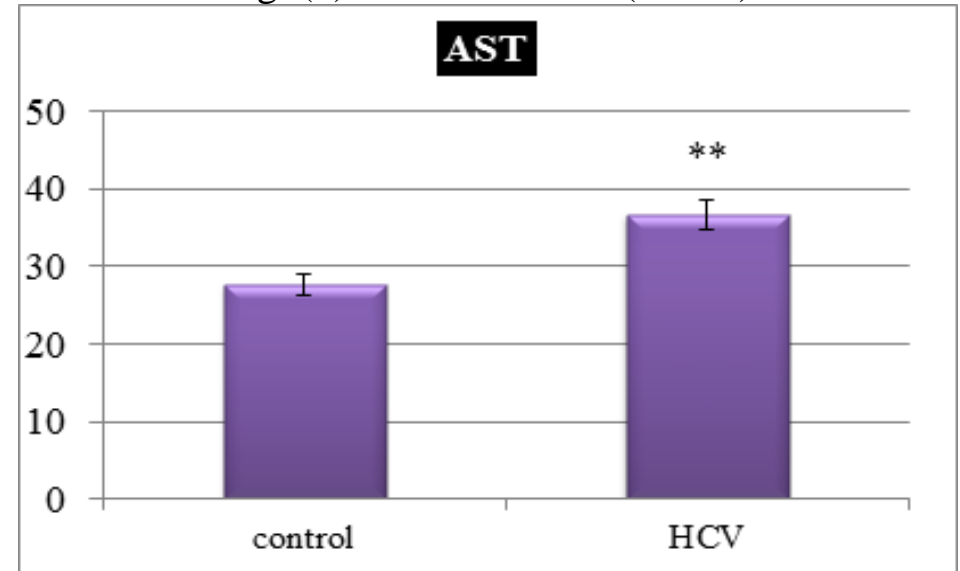

Fig. (6): Aspartate aminotransferase (AST) (U/L) in control and diseased samples 


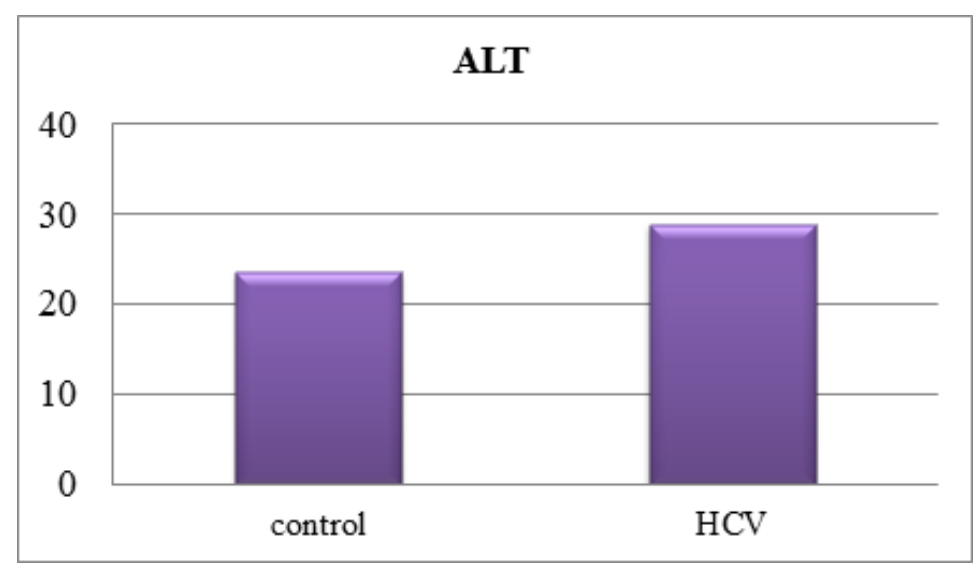

Fig. (7): Alanine aminotransferase (ALT) (U/L) in control and diseased samples.

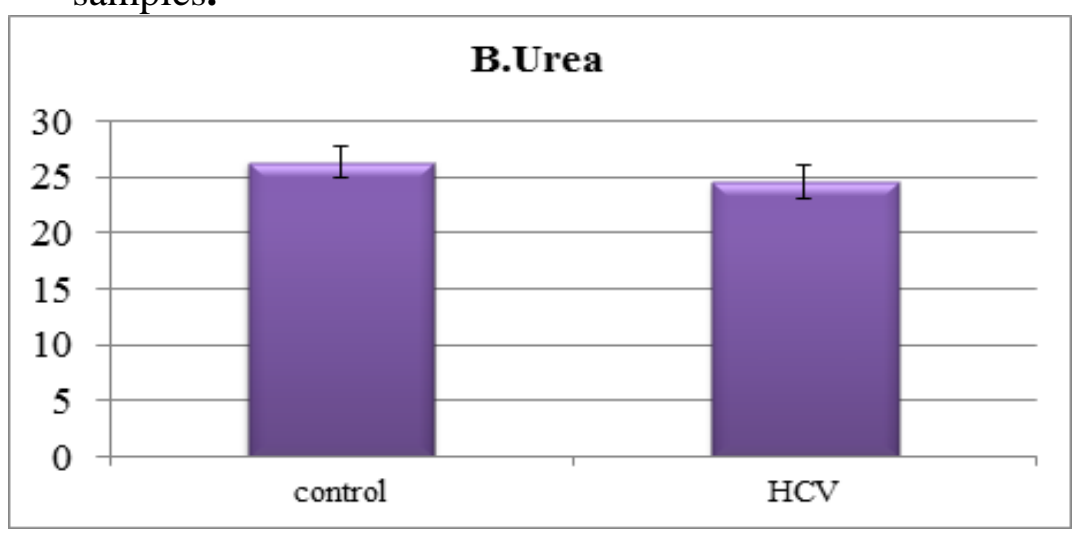

Fig. (8): Blood urea (mg/dL) in control and diseased sample

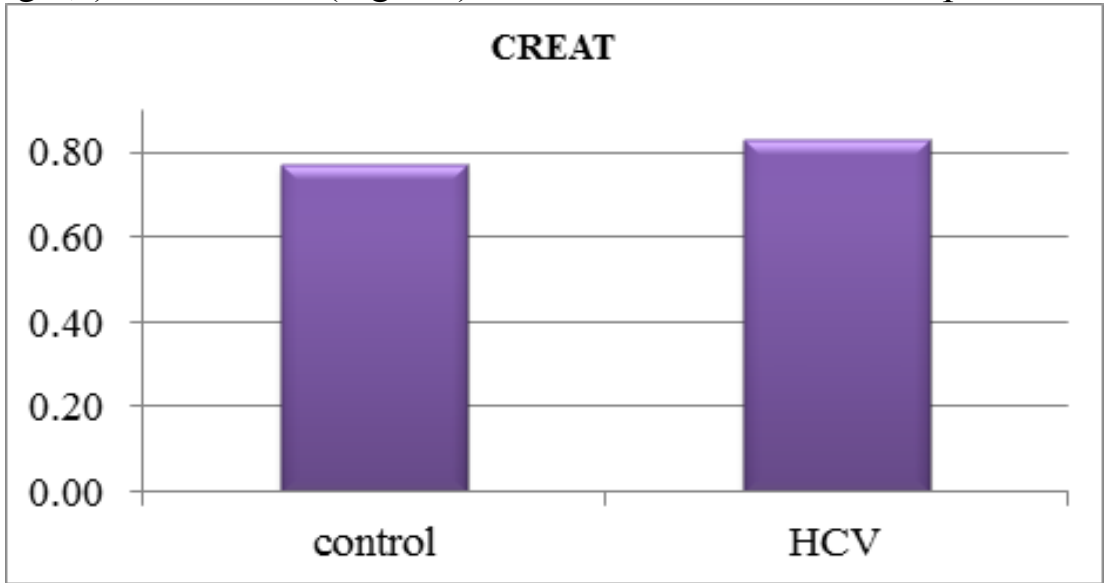

Fig. (9): Creatinine (mg/dL) in control and diseased samples. 


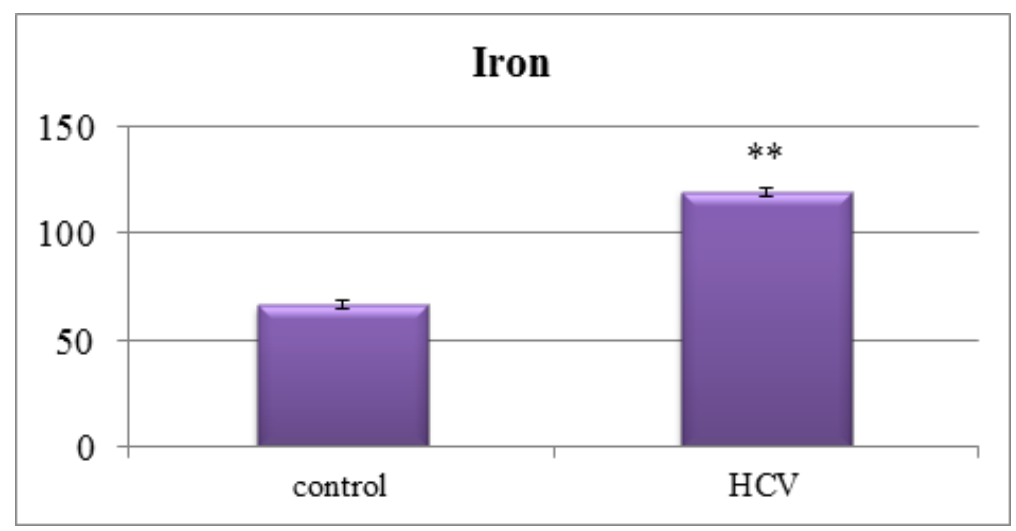

Fig. (10): Iron (Ug/dL) in control and diseased samples

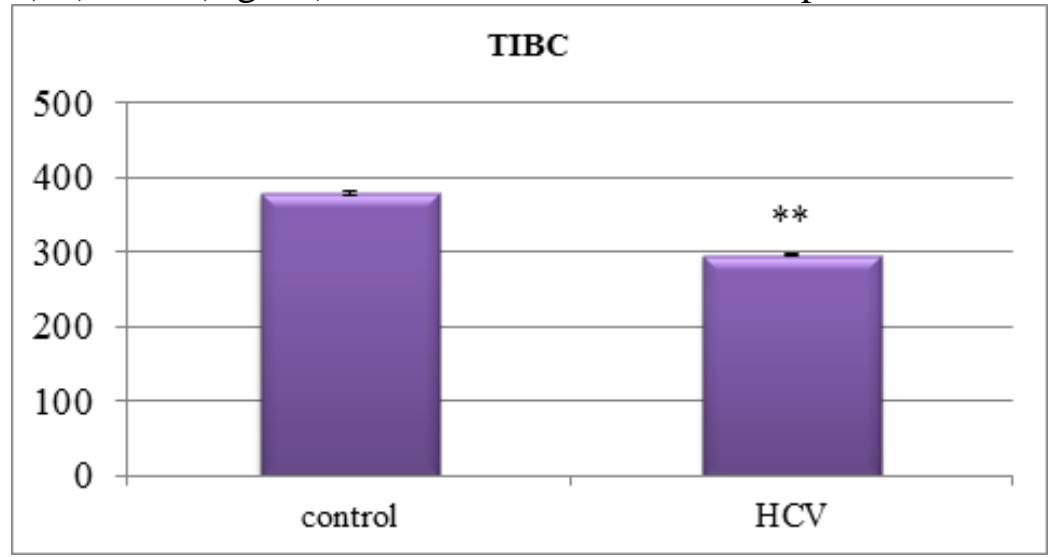

Fig. (11): Total iron binding capacity $(\mathrm{Ug} / \mathrm{dL})$ in control and diseased samples.

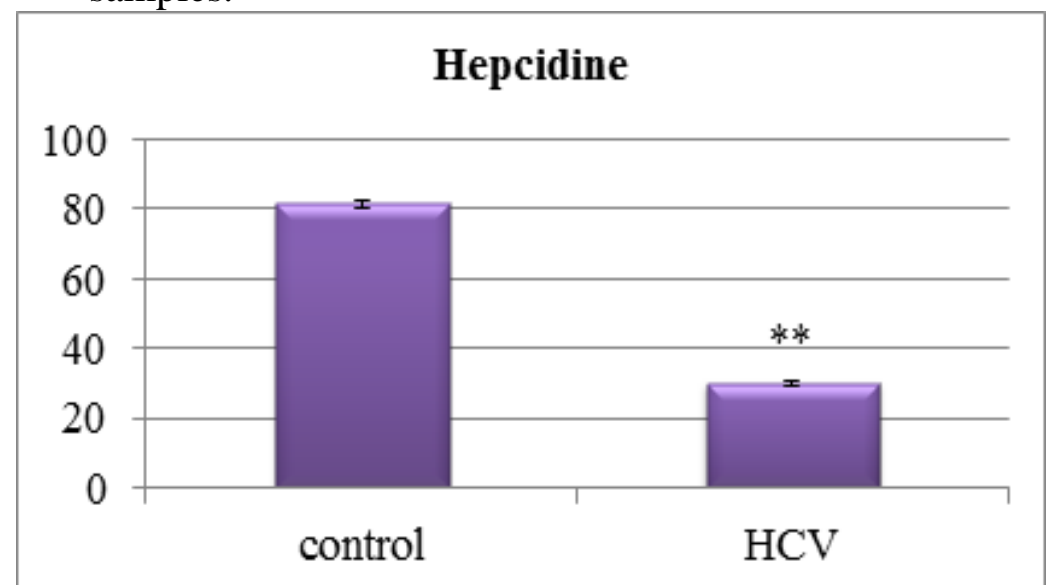

Fig. (12): Hepcidin level (ng/mL) in control and diseased samples . 


\section{CONCLUSION:}

Infection by $\mathrm{HCV}$ is a major health problem, threats many peoples all over the world. The liver is the main detoxifying organ of many metabolites; also it plays an important role in synthesis of proteins and production of biochemicals essential for digestion and growth in addition to its role in iron storage and iron metabolism. For iron homeostasis, hepcidin is synthesized in the liver and it is the key regulator for iron homeostasis.

\section{REFERENCES :}

Bazeed, F.B. ; E.H. Elsayed and A.A. Abd El-Aziz (2016): Evaluation of serum aminotransaminases and bilirubin in different treatment regimens for chronic hepatitis $\mathrm{C}$ virus. IOSR-JPBS.; 11(4): 20-26.

El-Zanaty, F. and A. Way (2009): Egypt Demographic and Health Survey 2008. Egyptian: Ministry of Health. Cairo: El-Zanaty and Associates and Macro International; p.31. Available from: http://dhsprogram.com/pubs/pdf/FR220/FR220.pdf.

Farid, S. ; S. Mohamed ; L. Rashid and D. Sbry (2012): A Key Regulator For Iron Homeostasis in chronic hepatitis C. The Egyptian J of Hospital Med., 49: 615- 627.

Flamm, S. ; A.M. Di Bisceglie ; A.C. Lyra ; M. Schwartz ; R.K. Reddy and P. Martin (2003): Hepatitis C-related hepatocellular carcinoma in the United States: influence of ethnic status. Am J Gastroenterol.; 98(9): 2060-3.

Frank, C. ; M.K. Mohamed and G.T. Strickland (2000): The role of parenteral antischistosomal therapy in the spread of hepatitis $\mathrm{C}$ virus in Egypt. Te Lancet; 355: 887-891.

Fujita, N. ; R. Sugimoto ; M. Takeo ; N. Urawa ; R. Mifuji and Tanaka H. (2007): Hepcidin expression in the liver: relatively low level in patients with chronic hepatitis C. Molecular Med.; 13(1-2):97-104.

Krause, A. ; S. Neitz ; H. Mägert; A. Schulz ; W. Forssmann and P. Schulz-Knappe (2000): LEAP-1, a novel highly disulfidebonded human peptide exhibits antimicrobial activity. FEBS Lett.; 480: 147-150.

Lambrecht, R.W. ; R.K. Sterling; D. Naishadham; A.M. Stoddard; T. Rogers and C. Morishima (2011): Iron levels in hepatocytes and portal tract cells predict progression and 
outcomes of patients with advanced chronic hepatitis C. Gastroenterol.; 140(5):1490-500.

Nagao, Y. and M. Sata (2010): Serum albumin and mortality risk in a hyperendemic area of HCV infection in Japan. Virol J.; 7: 375.

Nemeth, E. and T. Ganz (2009): The role of hepcidin in iron metabolism. Acta Haematol.;122:78-86.

Nemeth, E. ; S. Rivera; V. Gabayan ; C. Keller; S. Taudorf ; B.K. Pedersen and T. Ganz (2004): IL- 6 mediates hypoferremia of inflammation by inducing the synthesis of the iron regulatory hormone hepcidin. J Clin Invest.; 113: 1271- 1276.

Rossi, E. (2005): Hepcidin the iron regulatory hormone. Clin Biochem Rev.; 26: 47- 49.

Souza, R.M. ; L.A. Freitas ; A.C. Lyra ; C.F. Moraes ; E.L. Braga and L.G. Lyra (2006): Effect of iron overload on the severity of liver histologic alterations and on the response to interferon and ribavirin therapy of patients with hepatitis $\mathrm{C}$ infection. Braz J Med Biol Res.; 39: 79-83.

Spengler, U. and J. Nattermann (2007): Immunopathogenesis in hepatitis C virus cirrhosis. Clinical science; 112(3): 141-155.

Wahib, A.A. ; El-Nasr M.S. ; A.M. Mangoud ; A.M. El-Shazly and A.T. Morsy (2006): The liver profile in patients with hepatitis C virus and/or fascioliasis. J Egypt Soc Parasitol.; 36(2): 405-40.

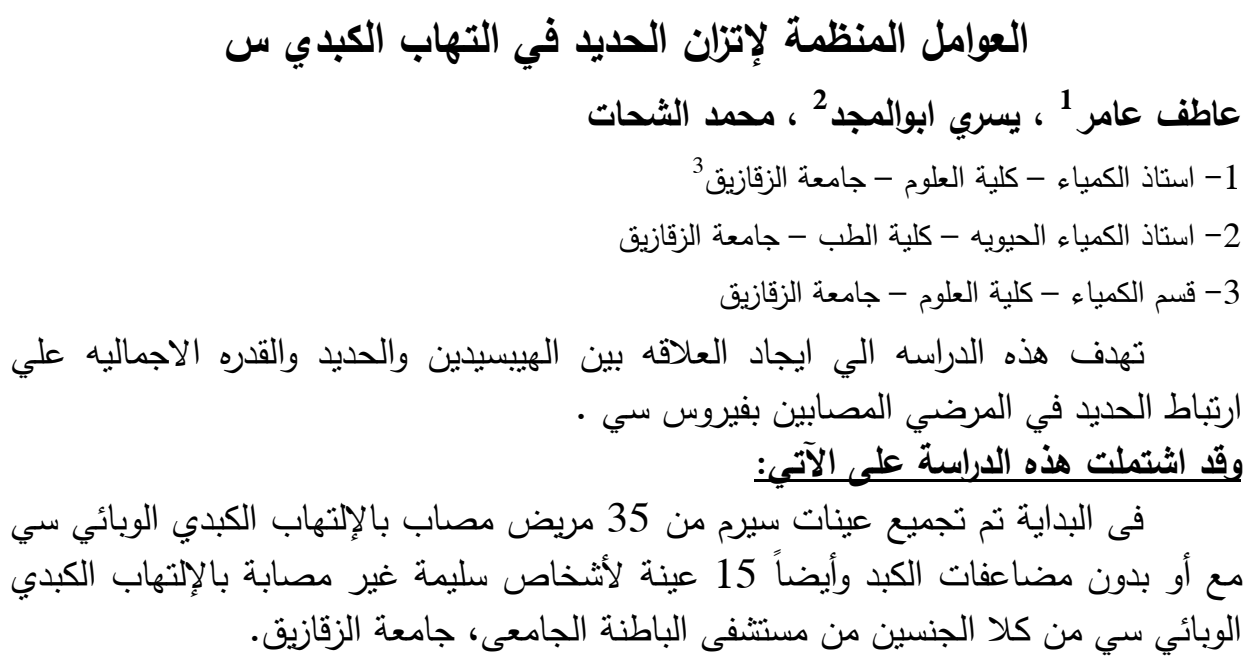


تم فحص عينات السيرم كيميائياً لمعرفة نأثير الإصابة بفيروس سي علي وظائف الكبد

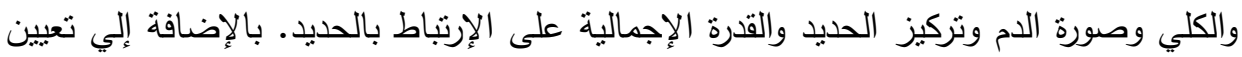
تركيز الهييسدين بواسطة الاليزا ومقارنة النتائج بالمجموعة السليمة الغيرمصابة.

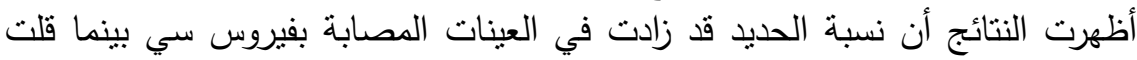
قدرة إرتباط الحديد الكلية في هذه العينات بالمقارنة مع المجموعة السليمة.

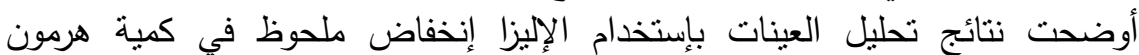

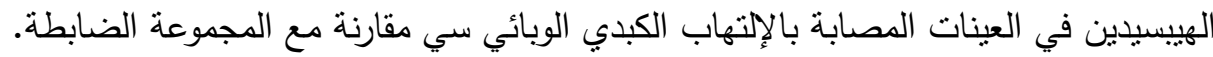

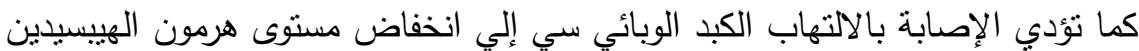

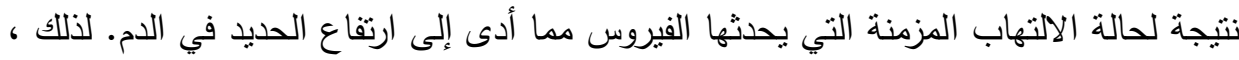

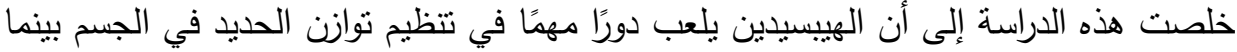
تؤدي الإصابة بالالتهاب الكبد الوبائي سي إلي إحداث خلل في هذا الإتزان 